\title{
AIP and MEN1 mutations and AIP immunohistochemistry in pituitary adenomas in a tertiary referral center
}

\author{
Adrian F Daly ${ }^{1, *}$, David A Cano ${ }^{2, *}$, Eva Venegas-Moreno ${ }^{2}$, Patrick Petrossians ${ }^{1}$, Elena Dios ${ }^{2}$, Emilie Castermans ${ }^{3}$, \\ Alvaro Flores-Martínez ${ }^{2}$, Vincent Bours ${ }^{3}$, Albert Beckers ${ }^{1, \dagger}$ and Alfonso Soto-Moreno ${ }^{2, \dagger}$ \\ 'Department of Endocrinology, Centre Hospitalier Universitaire de Liège, Liège Université, Liège, Belgium \\ 2Unidad de Gestión de Endocrinología y Nutrición, Instituto de Biomedicina de Sevilla (IBiS), Hospital Universitario Virgen del Rocío/CSIC/Universidad de \\ Sevilla, Sevilla, Spain \\ 3Department of Human Genetics, Centre Hospitalier Universitaire de Liège, Liège Université, Liège, Belgium
}

Correspondence should be addressed to A Beckers or A Soto-Moreno: albert.beckers@chuliege.be or alfonsom.soto.sspa@juntadeandalucia.es

*(A F Daly and D A Cano contributed equally to this work)

t(A Beckers and A Soto-Moreno equally oversaw this work)

\begin{abstract}
Background: Pituitary adenomas have a high disease burden due to tumor growth/ invasion and disordered hormonal secretion. Germline mutations in genes such as MEN1 and $A I P$ are associated with early onset of aggressive pituitary adenomas that can be resistant to medical therapy.

Aims: We performed a retrospective screening study using published risk criteria to assess the frequency of AIP and MEN1 mutations in pituitary adenoma patients in a tertiary referral center.

Methods: Pituitary adenoma patients with pediatric/adolescent onset, macroadenomas occurring $\leq 30$ years of age, familial isolated pituitary adenoma (FIPA) kindreds and acromegaly or prolactinoma cases that were uncontrolled by medical therapy were studied genetically. We also assessed whether immunohistochemical staining for AIP (AIP-IHC) in somatotropinomas was associated with somatostatin analogs (SSA) response.

Results: Fifty-five patients met the study criteria and underwent genetic screening for AIP/MEN1 mutations. No mutations were identified and large deletions/duplications were ruled out using MLPA. In a cohort of sporadic somatotropinomas, low AIP-IHC tumors were significantly larger $(P=0.002)$ and were more frequently sparsely granulated $(P=0.046)$ than high AIP-IHC tumors. No significant relationship between AIP-IHC and SSA responses was seen.

Conclusions: Germline mutations in AIPIMEN1 in pituitary adenoma patients are rare and the use of general risk criteria did not identify cases in a large tertiary-referral setting. In acromegaly, low AIP-IHC was related to larger tumor size and more frequent sparsely granulated subtype but no relationship with SSA responsiveness was seen. The genetics of pituitary adenomas remains largely unexplained and AIP screening criteria could be significantly refined to focus on large, aggressive tumors in young patients.
\end{abstract}

Key Words
- AIP
- FIPA
- acromegaly
- somatostatin analog
- resistance
- MEN1
- pituitary adenoma
- pasireotide

Endocrine Connections (2019) 8, 338-348

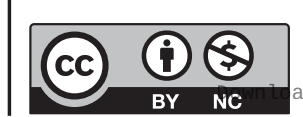

This work is licensed under a Creative Commons Attribution-NonCommercial 4.0 International License. ded from Bioscientifica.com at 04/26/2023 07:08:33AM 


\section{Introduction}

Clinically apparent pituitary adenomas are present in about 1:1000 of the general population in Europe; the most frequent sub-types are prolactinomas, non-secreting adenomas and somatotropinomas, while Cushing's disease and thyrotropinomas are rarer $(1,2,3)$. Treatment of pituitary adenomas varies according to the pituitary adenoma sub-type. Responses to therapy are variable due to heterogeneity among patient profiles and tumor characteristics. For instance, acromegaly patients may be resistant to somatostatin analogs (SSA) that target the somatostatin receptor subtype 2 (SST2), while a small proportion of prolactinoma patients may not respond to labeled doses of dopamine agonists (DA). Hence, multimodal therapy involving neurosurgery, medical therapy and radiotherapy can be needed to treat pituitary adenomas $(4,5,6,7)$.

There is an increased likelihood of aggressive pituitary adenoma characteristics (early age at diagnosis, large tumor size, increased invasiveness) in association with a number of germline genetic mutations. Of these, the aryl hydrocarbon receptor-interacting protein (AIP) gene and the MEN1 gene have been widely studied in the clinical setting. Germline MEN1 mutations lead to multiple endocrine neoplasia type 1 (MEN1), which is characterized by tumors occurring in the parathyroids, enteropancreatic endocrine tissues and anterior pituitary (8). MEN1 mutations can be associated with early onset and relatively difficult-to-treat pituitary adenomas $(9,10,11)$. Germline AIP mutations (AIPmut) or deletions generally predispose to acromegaly, usually presenting as familial isolated pituitary adenomas (FIPA) (12). Notably, AIPmutassociated somatotropinomas occur at a significantly younger age and are larger and more extensive than non-AIPmut acromegaly cases (13). These characteristics lead to a high rate of gigantism among AIPmut-affected patients (14). AIPmut-associated acromegaly patients have a significantly worse response to treatment with SST2specific SSA compared with AIP wild-type acromegaly controls, both in terms of smaller IGF- 1 decreases and less tumor shrinkage. In acromegaly patients without AIPmut, it has also been suggested that AIP immunohistochemical score in surgically-resected somatotropinomas may be a good indicator of whether patients are SST2-specific SSA responders $(15,16)$.

Screening studies in the general clinical population of pituitary adenomas are not particularly useful as AIPmuts are rare $(0-4 \%$ positive cases) $(17,18,19)$. Several recommendations have been made regarding the ideal characteristics of patients to refer for AIPmut testing, including pituitary gigantism patients, FIPA families, pediatric pituitary adenoma patients and those with pituitary macroadenomas (particularly acromegaly), occurring $\leq 30$ years of age $(20,21,22)$. Given the characteristic resistance to SST2-specific SSA in AIPmut acromegaly, it has been suggested that such patients might be informative for specific screening. Oriola $e t$ al. reported that $8 \%$ of acromegaly patients who had failed surgery and SSA had AIP gene variants (23). To address the practicality of these screening factors in the clinical setting, we analyzed AIP and MEN1 status in a cohort of pituitary adenoma patients from a large regional referral population. We also assessed the relationship between tumoral immunohistochemical staining for AIP, disease characteristics and SST2-specific SSA hormonal responses in sporadic acromegaly patients.

\section{Patients and methods}

This was a single-center, retrospective study performed in patients from the Department of Endocrinology, Hospital Universitario Virgen del Rocío, Seville, Spain. Patients diagnosed at any time with a pituitary adenoma were eligible, up to a cut-off date of July 2017.

Data on each patient included sex, date of birth, age at diagnosis, tumor size (maximum diameter), tumor classification (micro-or macroadenomas), treatment (surgery, medical therapy, radiotherapy) and the magnitude of hormonal responses to treatment with SSA (including \% reduction in IGF-1 from baseline; GH levels on an oral glucose tolerance test), where relevant.

\section{Inclusion criteria}

We undertook a retrospective analysis of the patient population treated for pituitary adenomas who were in follow-up at the study center $(n=903)$.

We identified individuals that fell into the following categories:

1. Somatotropinomas and prolactinomas that were hormonally resistant to medical treatment.

Patients with documented acromegaly, defined as a failure to suppress GH following an oral glucose tolerance test, an age/sex-corrected IGF-1 level above the upper limit of the normal range and a pituitary tumor identified on magnetic resonance imaging (MRI) at baseline were assessed. Lack of hormonal

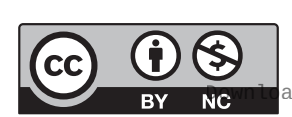

This work is licensed under a Creative Commons Attribution-NonCommercial 4.0 International License. ded from Bioscientifica.com at 04/26/2023 07:08:33AM 
control (SSA resistance) was defined as an IGF-1 above the upper limit of normal for age and sex, and a nonsuppressed GH following an oral glucose load following at least 3 months of treatment with octreotide or lanreotide at their maximum labeled/tolerated dose in the pre-operative or adjuvant setting. Patients with prolactinomas had to have serum prolactin levels that were chronically elevated above the upper limit of normal in association with a macroadenoma on MRI. Lack of hormonal control (DA resistance) was defined as per Molitch (17) as a failure to achieve normalization of serum prolactin at the highest labeled dose of cabergoline ( $2 \mathrm{mg} /$ week). Resistance to medical therapy with SSA or DA in terms of tumor shrinkage was not included as a criterion in this study.

2. Early-onset pituitary adenomas of any clinical sub-type. a. Patients with pituitary tumors that occurred at or before 18 years of age (pediatric pituitary tumors). Pituitary tumors could be of any clinical subtype and of any diameter, as long as a tumor was confirmed on MRI at diagnosis; this subgroup also included pituitary gigantism patients.

b. Patients with MRI-confirmed pituitary macroadenomas that occurred (first symptoms or diagnosed) $\leq 30$ years of age.

3. FIPA kindreds.

Patients that had one or more related family members with a pituitary adenoma on clinical history in the absence of MEN1 or other syndromes.

\section{Genetic studies}

Genetic analyses of the AIP and MEN1 genes were performed using leukocyte-derived DNA as described previously (24). In addition to sequence changes, all patients underwent studies to screen for exon-level or whole gene deletions or duplications using multiplex ligation-dependent probe amplification (MLPA) kit P244 (SALSA P244 Probemix, MRC-Holland) according to the manufacturer's instructions. In one patient with an AIP sequence variant DNA was extracted from the pituitary adenoma to test for loss of heterozygosity $(\mathrm{LOH})$ at the AIP locus. Sequence variations were assessed and graded according to the American College for Medical Genetics guidelines. In the case where class 3 (variant of unknown significance), class 4 (likely pathogenic) and class 5 (pathogenic) sequence changes were identified, related family members underwent clinical screening for disease features and where appropriate, were offered genetic testing. Patients provided informed consent for the study, which was approved by the Ethics Committees of the CHU de Liège and the Hospital Universitario Virgen del Rocío.

\section{Immunohistochemistry for AIP}

We undertook a specific study of immunohistochemistry for AIP (AIP-IHC) in a series of 51 somatotropinomas operated on at the Hospital Universitario Virgen del Rocío, Seville, Spain. These 51 patients comprise part of a cohort of patients described in Venegas-Moreno et al. (25). All acromegaly patients included in this study were surgically pre-treated with SSA (octreotide or lanreotide) for $>8$ weeks, following the usual clinical practice in our hospital. IHC was performed using a mouse monoclonal anti-AIP antibody (1:500 dilution; NB100-127 (B35-2), Bio-Techne R\&D Systems S.L.U., Madrid, Spain) as described in $(16,26,27)$. A semi-quantitative score for AIP staining intensity was applied: $0=$ negative; $1=$ weak; 2 =moderate; 3 =strong. This was multiplied by a score for expression patterning of $1=$ patchy and $2=$ diffuse to provide a final score ranging from 0 to 6 . A low overall AIP immunostaining result was defined by a semi-quantitative AIP-IHC score $\leq 2$, whereas high AIP-IHC was defined as a score of $\geq 3$. For Ki-67 quantification, we counted at least 1000 cells in an area with the highest cell density. Results are expressed as the percentage of tumor cells with positive nuclei of the total number of cells. Cytokeratin CAM5.2 characteristics and staining pattern were used to classify somatotropinomas as sparsely or densely granulated tumors. The densely granulated tumors had a diffuse perinuclear CAM5.2 staining pattern in $>70 \%$ of tumor cells, while sparsely granulated adenomas had a paranuclear and spherical pattern in $>70 \%$ of cells.

\section{Results}

\section{Patient characteristics}

As noted in Fig. 1, from a total population of 903 pituitary adenoma patients, 67 met the inclusion criteria for the genetic study and 55 of these underwent genetic testing. Details of the patient population are shown in Table 1. Among the 55 participants, there were eight FIPA families; seven were two-member families, and one was a threemember acromegaly-prolactinoma kindred. There were 12 pediatric pituitary adenoma patients, most of whom had Cushing's disease, while one had gigantism. Fifteen patients had a pituitary macroadenoma that presented $\leq 30$ years of age, 17 patients had SSA-resistant acromegaly and three had DA-resistant prolactinomas. The median age

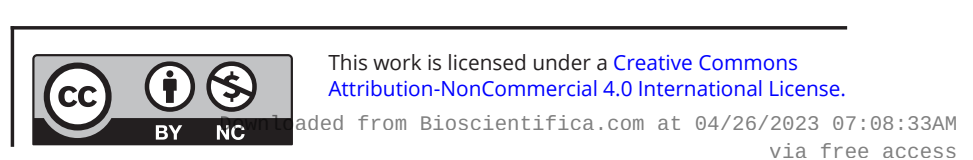




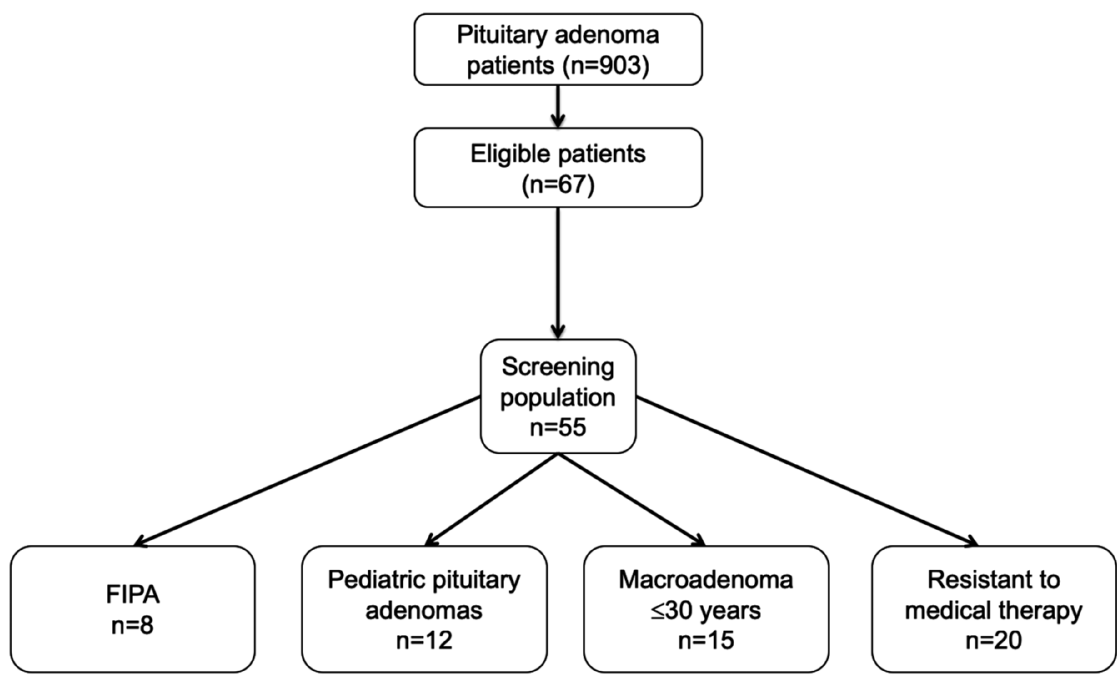

\section{Figure 1}

Disposition of study subjects according to screening characteristics. at diagnosis of the group was 27 years (range 10-62 years) and most patients were female $(n=39)$. All but five of the patients had macroadenomas; four microadenomas occurred in children with Cushing's disease aged 12-15 years at diagnosis and one was in a FIPA patient.

\section{Genetic results}

The screening study was undertaken to assess whether patients with the screening criteria had AIP and MEN1 mutations/deletions, but no pathological genetic variants were found in AIP or MEN1 in any of the 55 patients. Similarly, on MLPA, no deletions of AIP or MEN1 or their individual exons were found. Three subjects were heterozygous for the p.D172D AIP variant (rs2276020), and one had the p.D44D variant (rs11822907); both variants are considered benign or likely benign in nature. One patient had the p.A299V (rs148986773) change in $A I P$, which has been reported previously in clinical studies. It is considered more likely to be benign, and based on tumor DNA studies, we confirmed that there was no loss of heterozygosity (LOH) at the AIP locus, which further supports this non-pathological classification. Family screening demonstrated the p.A299V change in an asymptomatic parent and in a sibling. There was one MEN1 variant found in one pediatric patient with Cushing's disease, p.R171Q (rs607969), although this too is considered as benign/likely benign.

\section{Immunohistochemistry of AIP in sporadic acromegaly}

A total of 51 somatotropinomas from sporadic acromegaly patients were analyzed. These patients were not selected according to tumoral or other disease characteristics and their baseline clinical features are shown in Table 2. Forty-five tumors were macroadenomas. Nine of the adenomas displayed both $\mathrm{GH}$ and prolactin expression while the remaining 42 were purely GH-secreting tumors. Representative images of AIP immunohistochemistry in normal pituitary and in somatotropinomas with different semiquantitative AIP-IHC scores are shown in Fig. 2. All somatotropinomas displayed some degree of AIP immunoreactivity. Thus, none of the patients were classified as score 0. Twenty-four somatotropinomas exhibited low AIP-IHC scores $(\leq 2)$. Tumor size was significantly greater in the low AIP-IHC group (median $=25 \mathrm{~mm}$ (IQR, 15-35.8)) as compared with the high AIP-IHC patients (median=15 mm (IQR, 10-20.3); $P=0.002)$. No other statistically significant differences in gender, age and $\mathrm{GH}$ or IGF-1 levels at diagnosis were observed between low and high AIP-IHC patient groups (Table 2).

Data to determine the response to SSA was available for 39 patients at 3 months of treatment (26 before surgery and 13 as adjuvant therapy) and for 35 patients at 6 months of treatment (18 before surgery and 17 as adjuvant therapy). As there were no differences in the magnitudes of response to SSA between patients treated preoperatively or adjuvantly (25), we analyzed all of the SSA response data as a group at 3 months and then at 6 months. No differences in the percentage reduction in IGF-1 were observed between the low and high AIP-IHC groups after either 3 or 6 months of SSA treatment (Fig. 2).

\section{Discussion}

In this study, we assessed the prevalence of germline mutations of AIP and MEN1 in a focused group of

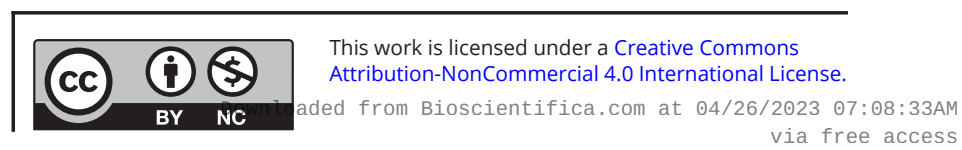




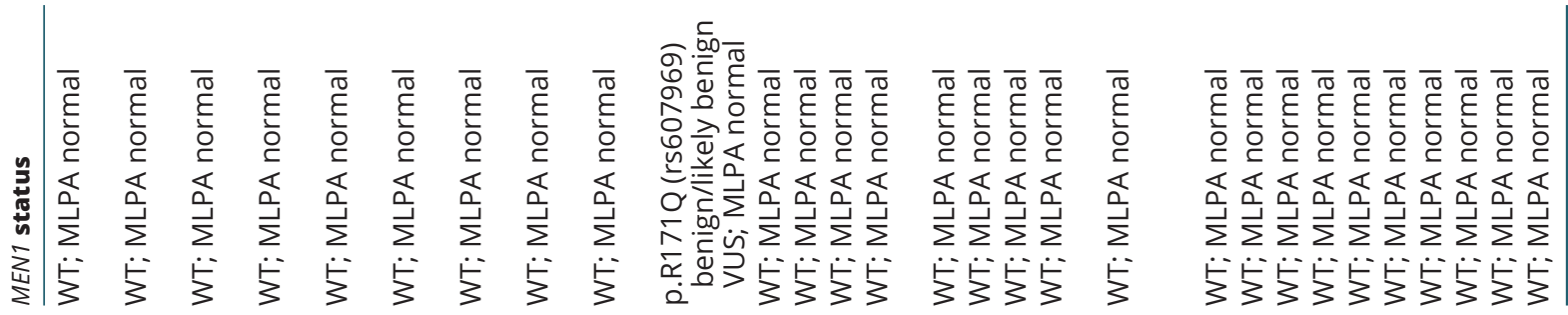

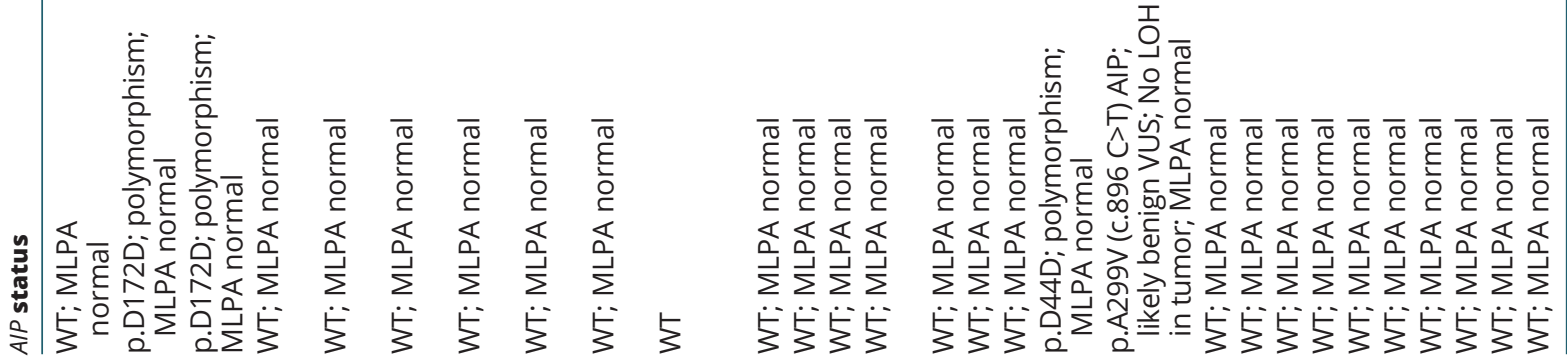

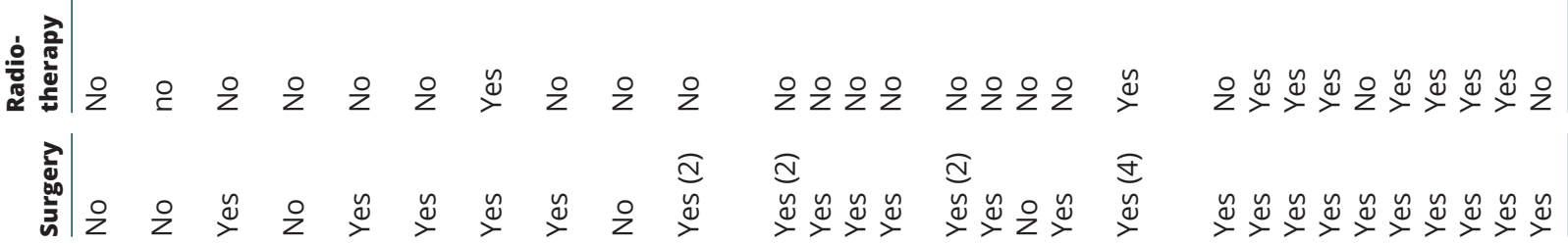
ํํำ

$\stackrel{m}{\sim} \stackrel{n}{\sim} \stackrel{ }{\sim}$ ㅇํำ

\section{范 \\ :}

\section{(1)}

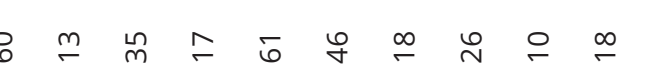

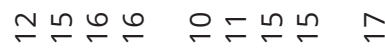

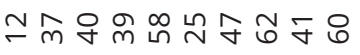

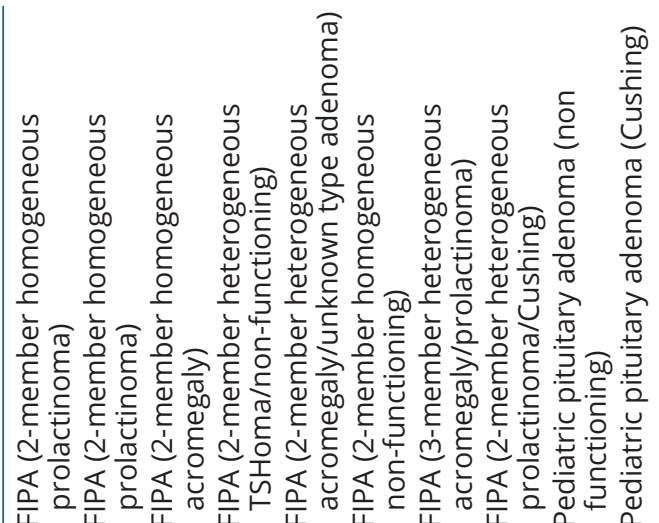

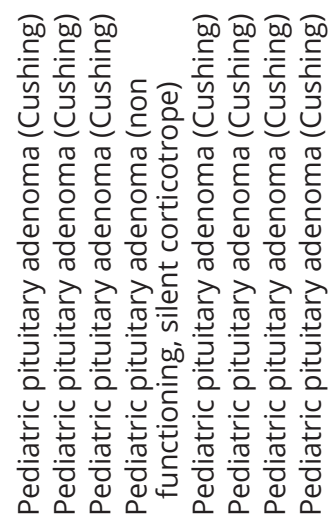
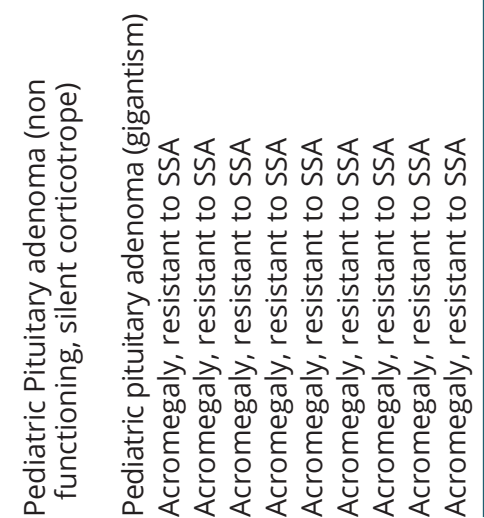


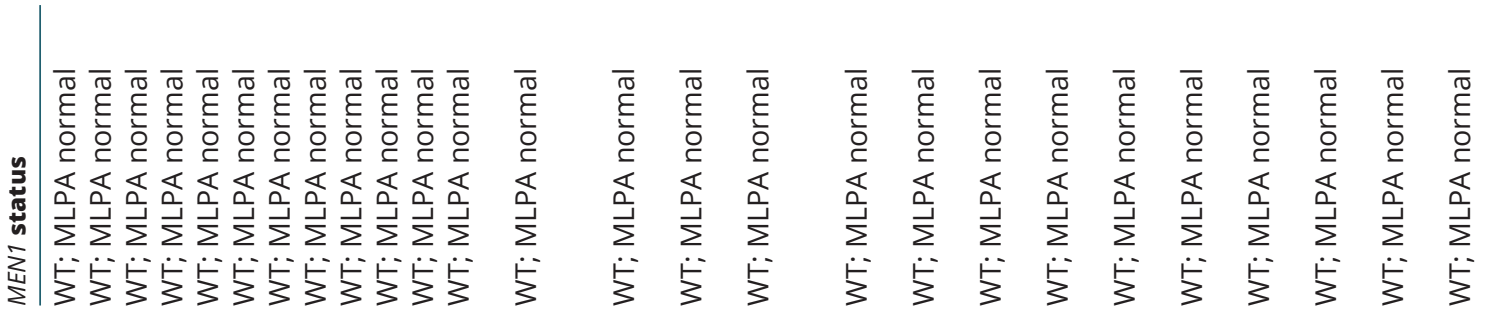

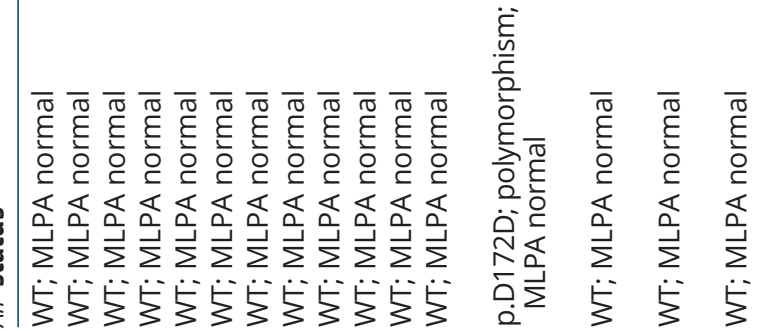
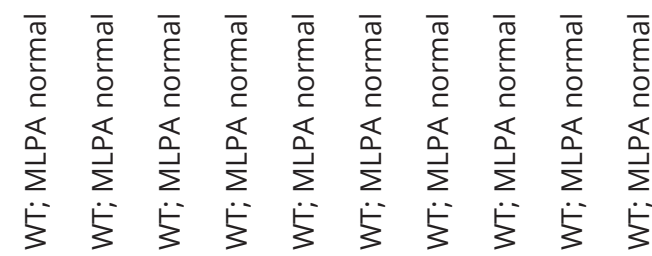

을

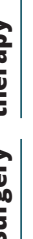

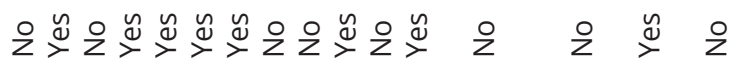

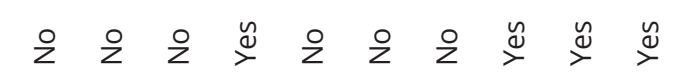

ฮิฮล

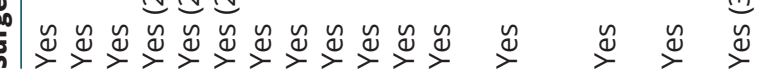

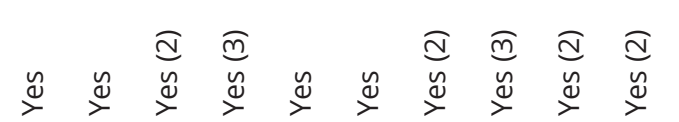
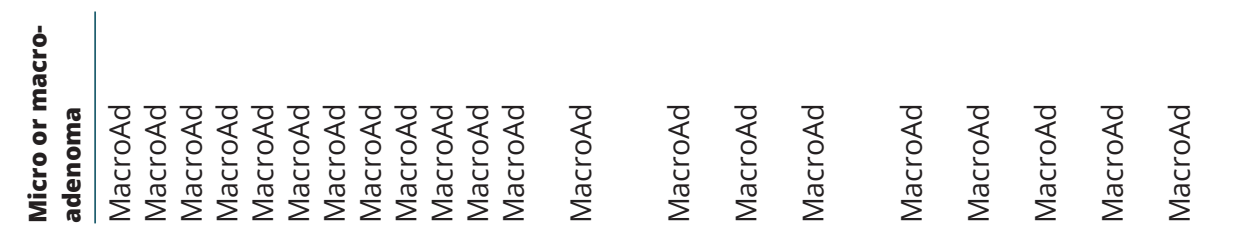

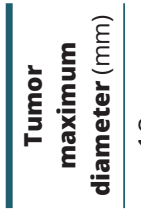

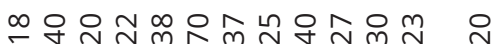

$\stackrel{n}{\sim} \stackrel{n}{\sim}$

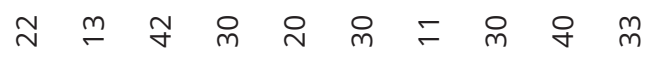

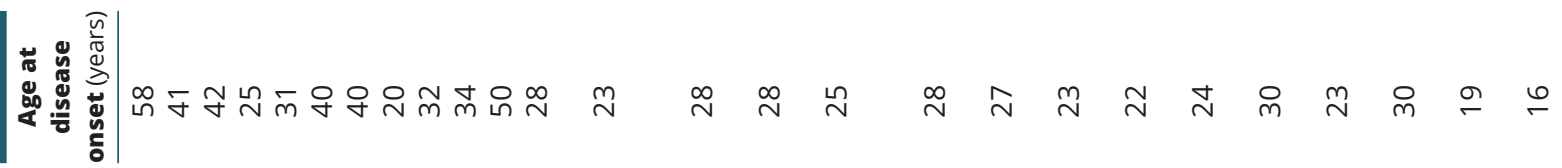
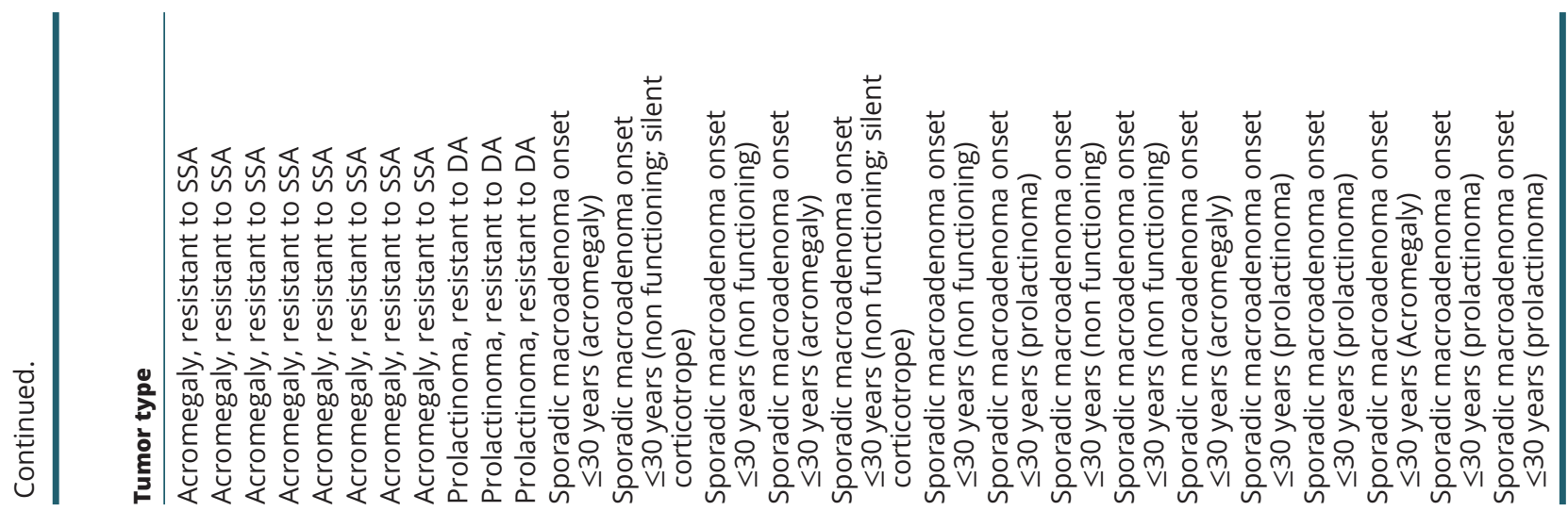

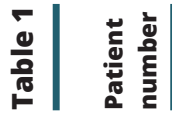

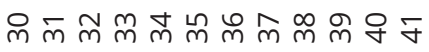


Table 2 Baseline characteristics of 51 acromegaly patients studied using AIP immunohistochemistry.

\begin{tabular}{l}
\hline Characteristics \\
\hline Sex (number, male/female) \\
Age at diagnosis (years, median, IQR) \\
Maximum tumor diameter at diagnosis (mm, median, IQR) \\
GH at diagnosis (ng/mL, median, IQR) \\
IGF-1 at diagnosis (\%ULN, median, IQR) \\
Treatment duration (months, median, IQR) \\
Ki-67 index (\%, median, IQR) \\
GH-producing histological subtypes (number, sparsely/densely \\
granulated)
\end{tabular}

\begin{tabular}{c}
\hline Low AIP-IHC \\
\hline $11 / 13 \mathrm{M}$ \\
$37(32.5-42.5)$ \\
$25(15-35.8)$ \\
$20.5(9.9-44.3)$ \\
$280(238-343)$ \\
$6(2-10.5)$ \\
$0.4(0.3-1)$ \\
$12 / 7$
\end{tabular}

\begin{tabular}{c}
\hline High AIP-IHC \\
\hline $15 / 12$ \\
$40(31-48)$ \\
$15(10-22.3)$ \\
$22.5(8.4-40)$ \\
$228(182-311)$ \\
$5.5(2.8-11.5)$ \\
$0.2(0.1-1)$ \\
$9 / 18$
\end{tabular}

\begin{tabular}{c} 
P-Value \\
\hline 0.488 \\
0.515 \\
$\mathbf{0 . 0 0 2}$ \\
0.852 \\
0.163 \\
0.718 \\
0.143 \\
$\mathbf{0 . 0 4 6}$
\end{tabular}

Data are presented as medians with interquartile ranges (IQR). Bold indicates statistical significance.

ULN, upper limit of normal for age- and gender-matched IGF-1 levels.

55 patients with familial and sporadic isolated pituitary adenomas from a large tertiary referral center in Seville, Spain. The group was selected based on suggested criteria for patients that had a potential for having AIP and MEN1 mutations. The study cohort was young overall (median age 27 years) with large pituitary adenomas (median maximum diameter $22 \mathrm{~mm}$ ) and included eight new FIPA families with 2-3 affected members. None of the 55 patients had germline mutations in AIP or MEN1 and no cases of AIP/MEN1 deletions were found.

The results of the current study, while at first glance 'negative', do provide important new and confirmatory information. When individual clinical centers are considering screening programs for pituitary adenoma patients, the relative importance of different proposed criteria need to be weighed. As in the current study, many new FIPA families can be identified at large tertiary
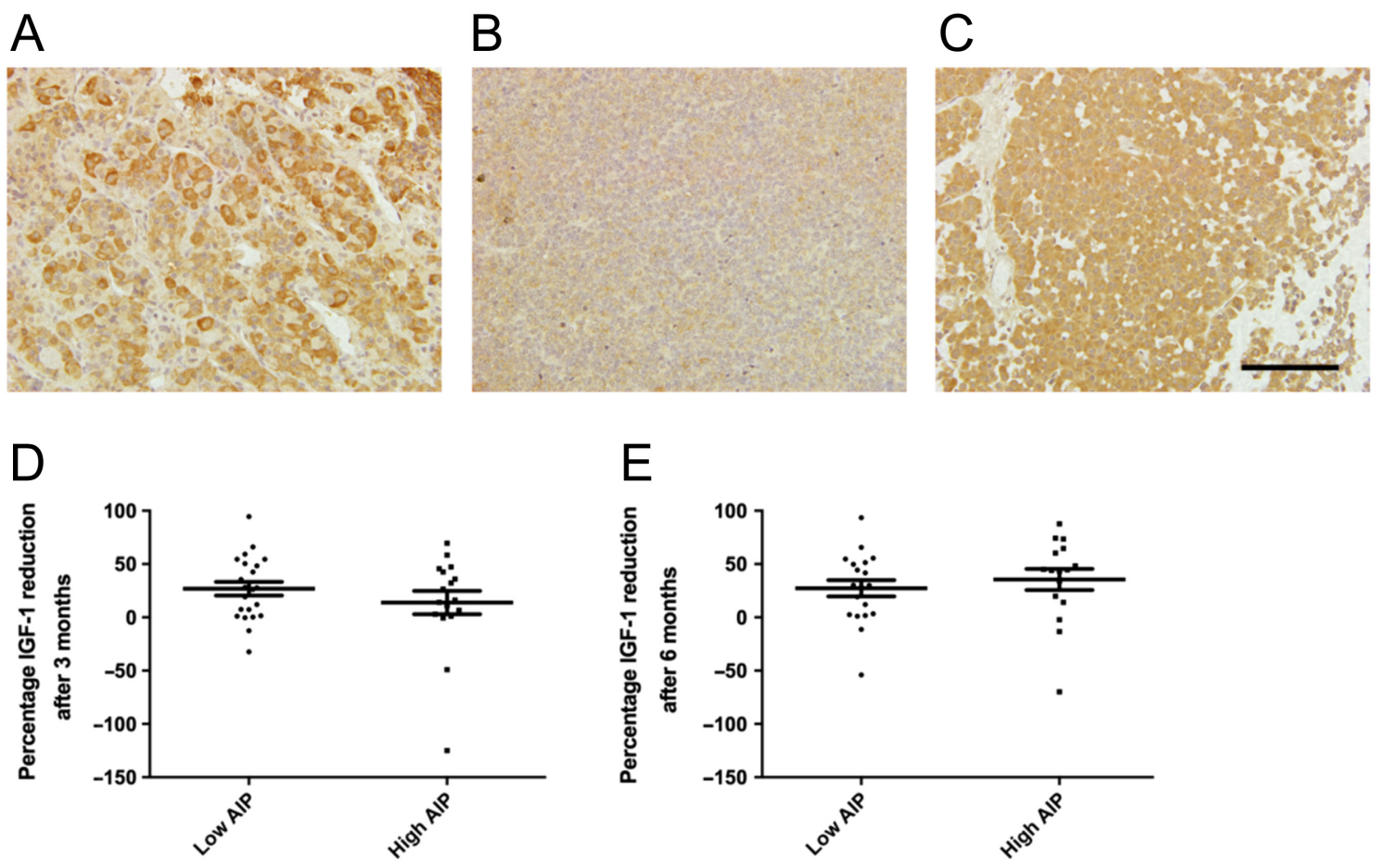

\section{Figure 2}

Immunohistochemical detection of AIP in somatotropinomas. Representative images of AIP immunohistochemistry in normal pituitary (A) and GH-secreting adenomas showing low (B; diffuse, weak) and high AIP expression (C; patchy, strong). Scale bar: $50 \mu m$ in C for A and B. (D) Comparison of IGF-1 percent reduction after 3 months of SSA treatment in tumors with low or high AIP-IHC expression. (E) Comparison of IGF-1 percent reduction after 6 months of SSA treatment with low or high AIP-IHC expression. Data points represent values for each individual patient. Mean and standard error (S.E.M.) values are shown.

https://ec.bioscientifica.com

https://doi.org/10.1530/EC-19-0027 (c) 2019 The authors Published by Bioscientifica Ltd

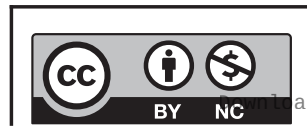

This work is licensed under a Creative Commons Attribution-NonCommercial 4.0 International License. ded from Bioscientifica.com at $04 / 26 / 2023$ 07:08:33AM 
referral centers, once the family history is specifically explored. Most such kindreds will be AIPmut negative, as about $80 \%$ of FIPA families remain genetically unexplained. Pediatric pituitary adenoma series report AIPmut rates of $11-20 \%(28,29,30,31)$. Most pediatric AIPmut-related pituitary adenomas are somatotropinomas with occasional prolactinomas or non-functioning tumors. Our pediatric cohort showed no AIPmut, which is probably because most had Cushing's disease, which confirms our previous findings that Cushing's disease is only very rarely associated with pathological AIPmut (29). This study underlines that AIPmut testing in pediatric patients with Cushing's disease has a low likelihood of being positive. In pediatric and adolescent patients with AIPmut-related pituitary adenomas, a typical presentation is with pituitary gigantism. Indeed, AIPmut are the single most important cause of pituitary gigantism, explaining $29 \%$ of cases, followed by X-linked acrogigantism (X-LAG) syndrome (10\%) and McCune Albright syndrome (5\%) (14). In the current cohort there was only one young patient with pituitary gigantism and he was negative for not only AIP/MEN1 mutations but also did not have X-LAG syndrome on array comparative genome hybridization (data not shown).

There is considerable uncertainty about how to best define 'young-onset' adult pituitary adenoma, with age cutoffs of 30 and 40 years having been proposed in the past $(19,30,31)$. While Preda et al. found a low rate (approximately $3 \%$ ) of AIPmut in a prospective, singlecenter study of patients aged $<40$ years, we reported a higher rate of nearly $12 \%$ among an international group of sporadic macroadenoma patients aged $<30$ years at diagnosis $(19,30)$. The contrast between the current results and those of our previous multicenter study may be explained by the relatively more severe patient profile of the AIPmut-positive patients identified in our previous study (30). While in the Seville sporadic cohort the median age was 27 years and the median tumor diameter was $23 \mathrm{~mm}$, in our international study the median age at diagnosis (18 years) and maximal tumor diameter $(39 \mathrm{~mm})$ were indicative of more severe disease. It may be that in order to optimize screening, the age of adult patients should be revised downward to well below 30 years at disease onset/diagnosis and that only patients with extensive and/or invasive macroadenomas should initially be considered for AIPmut analysis.

The topic of standardized screening criteria for AIP mutations was considered recently by Caimari et al. (32). They devised a risk stratification assessment for genetic screening that confirmed a number of factors such as young age at onset (including gigantism), FIPA, macroadenomas and GH excess (all $P \leq 0.001$ ). Young age at onset (19-30 years) alone was also an independent risk factor $(P=0.015)$. This stratification system points to certain very high-risk categories such as FIPA cases with macroadenomas occurring up to 18 years of age. In the absence of either FIPA, a macroadenoma or an age up to 18 years, the risk fell markedly in that stratification system. In the case where only moderate risk of an AIPmut is present, individual patient characteristics become important. In such instances, it is vital to take an individualized approach so as not to discount aggressive cases of large prolactinomas, non-functioning adenomas or apoplexy cases. No general risk stratification is foolproof, as shown by our current study: despite meeting the criteria for risk of AIPmut like the eight FIPA kindreds, no AIPmut cases were seen. Expectations about the likelihood of identifying mutation positive cases in a hospital cohort must take into account the underlying frequency from large collaborative datasets (e.g. only $20 \%$ of FIPA kindreds are AIPmut positive).

This study addressed whether adding the criteria of resistance to medical therapy with first-generation SSA in acromegaly patients, or maximum labeled dose cabergoline in prolactinoma patients could improve the identification of AIP or MEN1 mutations. Resistance to first-generation SSA is an established characteristic of AIPmut-related acromegaly (13). This may be caused by interference with important mediators of SST2 function, such as Gai2 or ZAC1 $(33,34)$. Oriola et al. previously reported a separate Spanish cohort of acromegaly patients with SSA resistance and noted a rate of AIPmut approaching $8 \%$ (23). The current study suggests that even in a population of acromegaly patients with macroadenomas, the addition of resistance to octreotide and lanreotide does not improve detection rates for AIP or MEN1 mutations. Given the identification of cabergolineresistant prolactinoma patients with AIP and MEN1 mutations in previous international studies $(10,13,35)$, we also screened for this criterion in the Seville population but only three patients were identified and none carried an AIP or MEN1 mutation/deletion.

Previous studies have reported that decreased tumoral AIP expression might be associated with poor response to first-generation SSA treatment of somatotropinomas, although results are inconsistent $(15,16,26,33,36)$. We did not find any such relationship between AIP IHC and response to SSA treatment using the same commercial AIP antibody and scoring system as in those previous studies. A possible explanation for the discrepancy is that all the

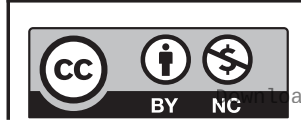

This work is licensed under a Creative Commons Attribution-NonCommercial 4.0 International License. ded from Bioscientifica.com at 04/26/2023 07:08:33AM 
acromegaly patients included in our IHC study received SSA pre-treatment while waiting for surgery. Pre-treatment with octreotide/lanreotide in acromegaly is associated with increased AIP protein expression $(26,33)$. Chahal et al. did not find an overall correlation between SSA response and AIP IHC in pretreated patients (33). JaffrainRea et al. reported significantly higher pre-operative GH and IGF-1 levels in a group of 67 acromegaly patients with low tumoral AIP staining; this difference was, however, not seen among a subgroup $(n=25)$ of patients who had not received preoperative SSA treatment (26). Furthermore, the only significant differences between low and high AIP IHC staining in non-SSA pretreated acromegaly patients in that study were in terms of increased invasiveness and suprasellar extension associated with low AIP staining. These inter-study differences reflect an imperfect correlation between AIP IHC and hormonal SSA responses. It should be noted that AIP IHC is quite variable in somatotropinomas, even among populations with germline AIPmut and is a poor tool for screening for possible AIPmut cases in a pathological setting (36). Given the fact that AIP-IHC results could be biased or influenced by SSA pretreatment, as noted earlier, studies with well-balanced groups of SSA pretreated and nonpretreated acromegaly patients would be helpful to clarify the role of the effect of SSA pretreatment on AIP-IHC. Subsequent studies could also explore the role of AIPIHC in predicting control of acromegaly with SSA under combined hormonal and tumor shrinkage criteria.

More consistently than predicting hormonal effects in acromegaly, low AIP IHC does seem to correlate with tumor aggressiveness, invasion and extension in somatotropinomas $(16,26)$. This echoes our finding of significantly larger tumor size in low vs high AIPIHC acromegaly groups. We also found that sparsely granulated adenomas were significantly more frequent in the low AIP-IHC group. Sparsely granulated adenomas have previously been shown to be associated with lower responses to octreotide/lanreotide and better responses to pasireotide and they predominate in AIPmut cases $(27,37$, 38). In sporadic acromegaly, it is difficult to know whether the relationship between low AIP-IHC and more frequent sparsely granulated tumors is a cause or an effect. Specific studies to fully explain the means by which AIPmut cause somatotrope tumorigenesis will hopefully cast some light on this issue.

In conclusion, our understanding of the genetics of pituitary adenomas is expanding quickly and many targets for screening are emerging. Due to this rapid progress, it is difficult to devise concrete guidelines for genetic testing in pituitary adenoma populations, although both expert recommendations and risk stratification models are helpful. While many pituitary adenoma patients with AIP and MEN1 mutations have been reported in the literature, the current study underlines that in the majority of FIPA and sporadic cases, no genetic cause is known. Furthermore, SSA resistance did not help to identify groups of patients with AIP and MEN1 mutations in this study. AIP-IHC is a promising pathological marker for somatotropinoma growth and invasion, although this study suggests that its role in predicting hormonal responses to SSA in acromegaly appears to be limited. Improved focus on patients with large and aggressive macroadenomas in the setting of pituitary gigantism, FIPA and pediatric-onset patients (apart from Cushing's disease) may help to refine genetic testing protocols. Nonetheless, other novel genetic factors in pituitary tumorigenesis remain to be identified.

\section{Declaration of interest}

The authors declare that there is no conflict of interest that could be perceived as prejudicing the impartiality of the research reported.

\section{Funding}

This research was supported by a grant from the Fonds d'Investissement pour la Recherche (FIRS) of the CHU de Liège, the JABBS Foundation, United Kingdom (to A B) and the ISCIII-Subdirección General de Evaluación y Fomento de la Investigación co-funded with Fondos FEDER (PI13/02043 to A S-M and PI16/00175 to A S-M and D A C). A S-M and D A C were also supported by grants from the Andalusian Ministry of Health (A-0003-2016, A-0006-2015, C-0015-2014 and RC-0006-2018).

\section{Acknowledgements}

The authors would like to thank Nathalie Sacre for work on sequencing and MLPA analyses. This research has been conducted using samples from the HUVR-IBiS Biobank (Andalusian Public Health System Biobank and ISCIII-Red de Biobancos PT13/0010/0056). The authors would like to thank Carolina Castilla and Fernando Carmona (HUVR-IBiS Biobank) for their outstanding technical help.

\section{References}

1 Daly AF, Rixhon M, Adam C, Dempegioti A, Tichomirowa MA $\&$ Beckers A. High prevalence of pituitary adenomas: a crosssectional study in the province of Liège, Belgium. Journal of Clinical Endocrinology and Metabolism 200691 4769-4775. (https://doi. org/10.1210/jc.2006-1668)

2 Gruppetta M, Mercieca C \& Vassallo J. Prevalence and incidence of pituitary adenomas: a population based study in Malta. Pituitary 201316 545-553. (https://doi.org/10.1007/s11102-012-0454-0)

3 Hoskuldsdottir GT, Fjalldal SB \& Sigurjonsdottir HA. The incidence and prevalence of acromegaly, a nationwide study from 1955 through 2013. Pituitary 201518 803-807. (https://doi.org/10.1007/ s11102-015-0655-4) 
4 Neggers SJCMM, de Herder WW, Feelders RA \& van der Lely AJ. Conversion of daily pegvisomant to weekly pegvisomant combined with long-acting somatostatin analogs, in controlled acromegaly patients. Pituitary 201114 253-258. (https://doi.org/10.1007/s11102010-0289-5)

5 Muhammad A, Coopmans EC, Delhanty PJD, Dallenga AHG, Haitsma IK, Janssen JAMJL, Van der Lely AJ \& Neggers SJCMM. Efficacy and safety of switching to pasireotide in acromegaly patients controlled with pegvisomant and somatostatin analogues: PAPE extension study. European Journal of Endocrinology 2018179 269-277. (https://doi.org/10.1530/EJE-18-0353)

6 Franck SE, Korevaar TIM, Petrossians P, Daly AF, Chanson P, JaffrainRéa ML, Brue T, Stalla GK, Carvalho D, Colao A, et al. A multivariable prediction model for pegvisomant dosing: monotherapy and in combination with long-acting somatostatin analogues. European Journal of Endocrinology 2017176 421-431. (https://doi.org/10.1530/ EJE-16-0956)

7 Giustina A, Chanson P, Kleinberg D, Bronstein MD, Clemmons DR, Klibanski A, Van der Lely AJ, Strasburger CJ, Lamberts SW, Ho KKY, et al. Expert consensus document: a consensus on the medical treatment of acromegaly. Nature Reviews Endocrinology $2014 \mathbf{1 0}$ 243-248. (https://doi.org/10.1038/nrendo.2014.21)

8 Thakker RV, Newey PJ, Walls GV, Bilezikian J, Dralle H, Ebeling PR, Melmed S, Sakurai A, Tonelli F, Brandi ML, et al. Clinical practice guidelines for multiple endocrine neoplasia Type 1 (MEN1). Journal of Clinical Endocrinology and Metabolism 201297 2990-3011. (https:// doi.org/10.1210/jc.2012-1230)

9 Goudie C, Hannah-Shmouni F, Kavak M, Stratakis CA \& Foulkes WD. 65 YEARS OF THE DOUBLE HELIX: Endocrine tumour syndromes in children and adolescents. Endocrine-Related Cancer 201825 T221-T244. (https://doi.org/10.1530/ERC-18-0160)

10 Cuny T, Pertuit M, Sahnoun-Fathallah M, Daly A, Occhi G, Odou MF, Tabarin A, Nunes ML, Delemer B, Rohmer V, et al. Genetic analysis in young patients with sporadic pituitary macroadenomas: besides AIP don't forget MEN1 genetic analysis. European Journal of Endocrinology 2013168 533-541. (https://doi.org/10.1530/EJE-12-0763)

11 Vergès B, Boureille F, Goudet P, Murat A, Beckers A, Sassolas G, Cougard P, Chambe B, Montvernay C, Calender A, et al. Pituitary disease in MEN type 1 (MEN1): data from the France-Belgium MEN1 multicenter study. Journal of Clinical Endocrinology and Metabolism $200287457-465$.

12 Daly AF \& Beckers A. Familial isolated pituitary adenomas (FIPA) and mutations in the aryl hydrocarbon receptor interacting protein (AIP) gene. Endocrinology and Metabolism Clinics of North America 201544 19-25. (https://doi.org/10.1016/j.ecl.2014.10.002)

13 Daly AF, Tichomirowa MA, Petrossians P, Heliövaara E, JaffrainRea ML, Barlier A, Naves LA, Ebeling T, Karhu A, Raappana A, et al. Clinical characteristics and therapeutic responses in patients with germ-line AIP mutations and pituitary adenomas: an international collaborative study. Journal of Clinical Endocrinology and Metabolism 201095 E373-E383. (https://doi.org/10.1210/ jc.2009-2556)

14 Beckers A, Petrossians P, Hanson J \& Daly AF. The causes and consequences of pituitary gigantism. Nature Reviews Endocrinology 201814 705-720 . (https://doi.org/10.1038/s41574-018-0114-1)

15 Kasuki L, Vieira Neto L, Wildemberg LEA, Colli LM, Castro M De, Takiya CM \& Gadelha MR. AIP expression in sporadic somatotropinomas is a predictor of the response to octreotide LAR therapy independent of SSTR2 expression. Endocrine-Related Cancer 201219 L25-L29 . (https://doi.org/10.1530/ERC-12-0020)

16 Kasuki Jomori de Pinho L, Vieira Neto L, Armondi Wildemberg LE, Gasparetto EL, Marcondes J, de Almeida Nunes B, Takiya CM \& Gadelha MR. Low aryl hydrocarbon receptor-interacting protein expression is a better marker of invasiveness in somatotropinomas than Ki-67 and p53. Neuroendocrinology 201194 39-48. (https://doi. org/10.1159/000322787)
17 Lecoq AL, Bouligand J, Hage M, Cazabat L, Salenave S, Linglart A, Young J, Guiochon-Mantel A, Chanson P \& Kamenický P. Very low frequency of germline GPR101 genetic variation and no biallelic defects with AIP in a large cohort of patients with sporadic pituitary adenomas. European Journal of Endocrinology 2016174 523-530. (https://doi.org/10.1530/EJE-15-1044)

18 Georgitsi M, Raitila A, Karhu A, Tuppurainen K, Makinen MJ, Vierimaa O, Paschke R, Saeger W, van der Luijt RB, Sane T, et al. Molecular diagnosis of pituitary adenoma predisposition caused by aryl hydrocarbon receptor-interacting protein gene mutations. PNAS 2007104 4101-4105. (https://doi.org/10.1073/pnas.0700004104)

19 Preda V, Korbonits M, Cudlip S, Karavitaki N \& Grossman AB. Low rate of germline AIP mutations in patients with apparently sporadic pituitary adenomas before the age of 40: a single-centre adult cohort. European Journal of Endocrinology 2014171 659-666. (https://doi. org/10.1530/EJE-14-0426)

20 Caimari F \& Korbonits M. Novel genetic causes of pituitary adenomas. Clinical Cancer Research 201622 5030-5042. (https://doi. org/10.1158/1078-0432.CCR-16-0452)

21 Beckers A, Rostomyan L \& Daly AF. Overview of genetic testing in patients with pituitary adenomas. Annales d'endocrinologie 201273 62-64. (https://doi.org/10.1016/j.ando.2012.03.028)

22 Lecoq AL, Kamenický P, Guiochon-Mantel A \& Chanson P. Genetic mutations in sporadic pituitary adenomas - what to screen for? Nature Reviews Endocrinology 201511 43-54. (https://doi. org/10.1038/nrendo.2014.181)

23 Oriola J, Lucas T, Halperin I, Mora M, Perales MJ, Alvarez-Escolá C, Paz dM, Díaz Soto G, Salinas I, Julián MT, et al. Germline mutations of AIP gene in somatotropinomas resistant to somatostatin analogues. European Journal of Endocrinology 2013168 9-13. (https:// doi.org/10.1530/EJE-12-0457)

24 Daly AF, Vanbellinghen JF, Khoo SK, Jaffrain-Rea ML, Naves LA, Guitelman MA, Murat A, Emy P, Gimenez-Roqueplo AP, Tamburrano G, et al. Aryl hydrocarbon receptor-interacting protein gene mutations in familial isolated pituitary adenomas: analysis in 73 families. Journal of Clinical Endocrinology and Metabolism 200792 1891-1896. (https://doi.org/10.1210/jc.2006-2513)

25 Venegas-Moreno E, Vazquez-Borrego MC, Dios E, Gros-Herguido N, Flores-Martinez A, Rivero-Cortés E, Madrazo-Atutxa A, Japón MA, Luque RM, Castaño JP, et al. Association between dopamine and somatostatin receptor expression and pharmacological response to somatostatin analogues in acromegaly. Journal of Cellular and Molecular Medicine 201822 1640-1649. (https://doi.org/10.1111/ jcmm.13440)

26 Jaffrain-Rea ML, Rotondi S, Turchi A, Occhi G, Barlier A, Peverelli E, Rostomyan L, Defilles C, Angelini M, Oliva MA, et al. Somatostatin analogues increase AIP expression in somatotropinomas, irrespective of Gsp mutations. Endocrine-Related Cancer 201320 753-766. (https://doi.org/10.1530/ERC-12-0322)

27 Leontiou CA, Gueorguiev M, van der Spuy J, Quinton R, Lolli F, Hassan S, Chahal HS, Igreja SC, Jordan S, Rowe J, et al. The role of the aryl hydrocarbon receptor-interacting protein gene in familial and sporadic pituitary adenomas. Journal of Clinical Endocrinology and Metabolism 200893 2390-2401. (https://doi.org/10.1210/jc.2007-2611)

28 Georgitsi M, de Menis E, Cannavo S, Makinen MJ, Tuppurainen K, Pauletto P, Curto L, Weil RJ, Paschke R, Zielinski G, et al. Aryl hydrocarbon receptor interacting protein (AIP) gene mutation analysis in children and adolescents with sporadic pituitary adenomas. Clinical Endocrinology 200869 621-627. (https://doi. org/10.1111/j.1365-2265.2008.03266.x)

29 Stratakis CA, Tichomirowa MA, Boikos S, Azevedo MF, Lodish M, Martari M, Verma S, Daly AF, Raygada M, Keil MF, et al. The role of germline AIP, MEN1, PRKAR1A, CDKN1B and CDKN2C mutations in causing pituitary adenomas in a large cohort of children, adolescents, and patients with genetic syndromes. Clinical Genetics $2010 \mathbf{7 8}$ 457-463. (https://doi.org/10.1111/j.1399-0004.2010.01406.x) 
30 Tichomirowa MA, Barlier A, Daly AF, Jaffrain-Rea ML, Ronchi C, Yaneva M, Urban JD, Petrossians P, Elenkova A, Tabarin A, et al. High prevalence of AIP gene mutations following focused screening in young patients with sporadic pituitary macroadenomas. European Journal of Endocrinology 2011165 509-515. (https://doi.org/10.1530/ EJE-11-0304)

31 Araujo PB, Kasuki L, Azeredo Lima CH de, Ogino L, Camacho AHS, Chimelli L, Korbonits M \& Gadelha MR. AIP mutations in Brazilian patients with sporadic pituitary adenomas: a single-center evaluation. Endocrine Connections 20176 914-925. (https://doi. org/10.1530/EC-17-0237)

32 Caimari F, Hernández-Ramírez LC, Dang MN, Gabrovska P, Iacovazzo D, Stals K, Ellard S, Korbonits M \& International FIPA consortium. Risk category system to identify pituitary adenoma patients with AIP mutations. Journal of Medical Genetics 201855 254-260. (https://doi.org/10.1136/jmedgenet-2017-104957)

33 Chahal HS, Trivellin G, Leontiou CA, Alband N, Fowkes RC, Tahir A, Igreja SC, Chapple JP, Jordan S, Lupp A, et al. Somatostatin analogs modulate AIP in somatotroph adenomas : the role of the ZAC1 pathway. Journal of Clinical Endocrinology and Metabolism 201297 E1411-E1420. (https://doi.org/10.1210/jc.2012-1111)

34 Tuominen I, Heliövaara E, Raitila A, Rautiainen MR, Mehine M, Katainen R, Donner I, Aittomäki V, Lehtonen HJ, Ahlsten M, et al. AIP inactivation leads to pituitary tumorigenesis through defective
Gxi-cAMP signaling. Oncogene 201534 1174-1184. (https://doi. org/10.1038/onc.2014.50)

35 Vroonen L, Jaffrain-Rea ML, Petrossians P, Tamagno G, Chanson P, Vilar L, Borson-Chazot F, Naves LA, Brue T, Gatta B, et al. Prolactinomas resistant to standard doses of cabergoline: a multicenter study of 92 patients. European Journal of Endocrinology 2012167 651-662. (https://doi.org/10.1530/EJE-12-0236)

36 Jaffrain-Rea ML, Angelini M, Gargano D, Tichomirowa MA, Daly AF, Vanbellinghen JF, D'Innocenzo E, Barlier A, Giangaspero F, Esposito V, et al. Expression of aryl hydrocarbon receptor (AHR) and AHR-interacting protein in pituitary adenomas: pathological and clinical implications. Endocrine-Related Cancer 200916 1029-1043. (https://doi.org/10.1677/ERC-09-0094)

37 Iacovazzo D, Carlsen E, Lugli F, Chiloiro S, Piacentini S, Bianchi A, Giampietro A, Mormando M, Clear AJ, Doglietto F, et al. Factors predicting pasireotide responsiveness in somatotroph pituitary adenomas resistant to first-generation somatostatin analogues: an immunohistochemical study. European Journal of Endocrinology 2016 174 241-250. (https://doi.org/10.1530/EJE-15-0832)

38 Bhayana S, Booth GL, Asa SL, Kovacs K \& Ezzat S. The implication of somatotroph adenoma phenotype to somatostatin analog responsiveness in acromegaly. Journal of Clinical Endocrinology and Metabolism 200590 6290-6295. (https://doi.org/10.1210/jc.20050998)

Received in final form 25 February 2019

Accepted 1 March 2019

Accepted Preprint published online 1 March 2019 https://ec.bioscientifica.com

https://doi.org/10.1530/EC-19-0027
(C) 2019 The authors Published by Bioscientifica Ltd
This work is licensed under a Creative Commons Attribution-NonCommercial 4.0 International License. ded from Bioscientifica.com at 04/26/2023 07:08:33AM 